\title{
Increased risk donor criteria: The time for change is now
}

The Public Health Service designation of increased risk donor (IRD) was created in 1994 and updated in 2013 to identify donors with increased of transmitting HIV, hepatitis B, and hepatitis C. While IRD designation was well intentioned, developments since its implementation have created several problems. Advancements in testing and treatment have dramatically changed the incidence and trajectory of patients with these diseases. The most recent evidence shows that IRD organs have equivalent graft and patient survival to non-IRD organs, but IRD kidneys are discarded at a 50\% higher rate than nonIRD kidneys. Given nearly $20 \%$ of organs are currently labeled as IRD, the cumulative result of the IRD designation is hundreds of IRD organs, that are safe for transplant and perform as well as non-IRD organs, go unused annually. Evidence has shown IRD designation creates negative bias among both provider and patients. The Public Health Service guidelines are currently in the process of being updated which presents a unique opportunity for the transplant community to strongly advocate for evidence-based changes which will improve access to transplant for all patients. Our letter to the editor briefly outlines the current problems with the IRD designation and proposes recommendations the transplant community should endorse.

In an effort to increase the number of life-saving transplants, the transplant community must re-evaluate the Public Health Service (PHS) designation of increased risk donor (IRD) organs. IRD kidneys are discarded at a $50 \%$ higher rate than non-IRD kidneys, despite equivalent survival. ${ }^{1,2}$ While the most comprehensive study on IRD utilization is dated and should be repeated using recent data, contemporary OPTN data show the discard rate of PHS kidneys has remained unchanged for over a decade leaving us to believe this issue remains unresolved. ${ }^{3}$ The Department of Health and Human Services is currently in the process of updating the PHS guidelines. Now is the time to advocate for change that will improve utilization of these vital organs.

The PHS guidelines were initially developed in 1994 to identify organs with increased risk of transmitting HIV and were revised in 2013 to include criteria to identify increased risk of hepatitis B and $\mathrm{C}$ (HBV and HCV) transmission. ${ }^{4}$ While the IRD designation was well intentioned, developments since their implementation have created several problems. The incidence of HIV and the risk of transmission has dropped dramatically, new direct-acting antiviral therapies have transformed HCV management, and nucleic acid testing (NAT) has significantly shortened the window period to detect infection. The guidelines provide no mechanism to account for the highly variable risks associated with specific behaviors. This has become increasingly important in the setting of the opioid epidemic with nearly $20 \%$ of donors currently labeled IRD. ${ }^{5}$ Most importantly, the guidelines clearly create cognitive biases in both providers and patients resulting in unequal utilization. ${ }^{6}$ National survey data suggest that transplant surgeons' perceptions of transmission risk do not correspond with actual risk. ${ }^{7}$ We believe a good proportion of the underutilization stems from the deleterious name which results in hundreds of IRD organs that are safe for transplant and perform as well as non-IRD organs, going unused annually.

In preparation for PHS to revise the IRD guidelines, the Advisory Committee on Blood and Tissue Safety and Availability recently proposed 11 recommendations to PHS for guideline improvements. ${ }^{8}$ While all 11 recommendations would be an improvement, we believe two in particular should be strongly advocated for by the transplant community:

1. Reduce the current risk behavior time frame from 12 months to 3 months as this is sufficient to detect blood-borne infection given modern testing.

2. Change the terminology of "increased risk donor" as this term creates a negative cognitive bias in both patient and provider. More neutral terminology, similar to "extended criteria donor," would allow a reframing of the discussion about risks of disease transmission, treatments if transmission occurs, and the risk of wait-list mortality. We suggest the term "PHS criteria donors" but encourage a discussion around whatever name is chosen as it has a significant effect on utilization.

The forthcoming PHS IRD guideline revision is a unique opportunity to impact access to kidney transplantation, and it is vital the transplant community strongly advocate for evidence-based changes to the guidelines to improve access to transplant for all patients.

\section{CONFLICTS OF INTEREST}

The authors do not report any conflicts of interest related to this study. 
${ }^{1}$ Department of Surgery, University of Michigan, Ann Arbor,

Michigan

${ }^{2}$ Center for Healthcare Outcomes and Policy, Ann Arbor

Michigan

\section{Correspondence}

Glenn K. Wakam, Department of Surgery, University of Michigan, 1500 E. Medical Center Dr., Ann Arbor, MI 48109.

Email: gwakam@med.umich.edu

\section{ORCID}

Glenn K. Wakam iD https://orcid.org/0000-0002-0950-9554

\section{REFERENCES}

1. Volk ML, Wilk AR, Wolfe C, Kaul DR. The "PHS Increased Risk" label is associated with nonutilization of hundreds of organs per year. Transplantation. 2017;101(7):1666-1669.

2. Fernandez HE, Chiles MC, Pereira M, et al. Outcomes for potential kidney transplant recipients offered public health service increased risk kidneys: a single-center experience. Clin Transplant. 2018;32(12):e13427.
3. Hart A, Smith JM, Skeans MA, et al. OPTN/SRTR 2018 annual data report: kidney. Am J Transplant. 2020;20(Suppl s1):20-130.

4. Seem DL, Lee I, Umscheid CA, Kuehnert MJ; Service USPH. PHS guideline for reducing human immunodeficiency virus, hepatitis $B$ virus, and hepatitis $C$ virus transmission through organ transplantation. Public Health Rep. 2013;128(4):247-343.

5. Kucirka LM, Bowring MG, Massie AB, Luo X, Nicholas LH, Segev $D L$. Landscape of deceased donors labeled increased risk for disease transmission under new guidelines. Am J Transplant. 2015;15(12):3215-3223.

6. Ros RL, Kucirka LM, Govindan P, Sarathy H, Montgomery RA, Segev DL. Patient attitudes toward CDC high infectious risk donor kidney transplantation: inferences from focus groups. Clin Transplant. 2012;26(2):247-253.

7. Kucirka LM, Namuyinga R, Hanrahan C, Montgomery RA, Segev DL. Provider utilization of high-risk donor organs and nucleic acid testing: results of two national surveys. Am J Transplant. 2009;9(5):1197-1204.

8. Fredrick J, Blumberg E, Brennan D, Custer B, Josephson C, Skinner M. Advisory Committee on Blood and Tissue Safety and Availability - April 16, 2019 Meeting Summary - Formulation of Committee Findings and Recommendations [Internet]. 2019 [cited 2019 Dec 26]. Available from:https://www.hhs.gov/oidp/advisory-committee/ blood-tissue-safety-availability/meeting-summary/2019-04-16/ index.html\#recommendations 